13

\title{
Using Argument Diagramming to Teach Critical Thinking in a First-Year Writing Course
}

\author{
Maralee Harrell and Danielle Wetzel
}

\section{Introduction}

The importance of teaching critical thinking skills at the college level cannot be overemphasized. Teaching a subcategory of these skills—argument analysis—we believe is especially important for first-year students with their college careers, as well as their lives, ahead of them. The struggle, however, is how to effectively teach argument analysis skills that will serve students in a broad range of disciplines.

Why is it so hard to teach argument analysis skills? Martin Davies articulates a good answer:

In addition to the complexities of distinguishing different parts of the argument, students must also deal with the complexities of academic language. The student must, in addition, be able to:

(1) Succinctly paraphrase claims;

(2) Distinguish premises from conclusions;

(3) Locate crucial hidden premises;

(4) Put the claims into the appropriate logical order;

(5) Show the inferential link(s) from premises to conclusions. (Davies 2009, 802-803)

The teaching method we want to advocate here is argument diagramming. There are, however, several different models of argument diagramming from which to choose. One of the most popular models was promoted by Stephen Toulmin in The Uses of Argument in 1958 (Toulmin 1958). Over the past several decades, for example, the Toulmin model has been adopted by English, rhetoric, and composition departments all over the United States. An alternative 
model for diagramming arguments, however, has recently gained some traction with teachers of critical thinking and informal logic. This model originated with Monroe Beardsley in 1950, was refined by James Freeman in the 1980s and 1990s (Freeman 1991), and is now known as the Beardsley-Freeman model.

This kind of argument diagram is a visual representation of the content and structure of an argument. For illustration, consider the following argument:

The ability to think critically is more important now than it has ever been. People have always had to make important decisions in their daily lives, but now, more than ever, these decisions can affect millions of others around the word, as well as many more millions in future generations. When we vote for particular criminal or national health policies, these decisions resonate through our communities. When we vote for candidates for particular political offices, these decisions can impact other people around the world who are affected by our foreign policy. And, when we vote for particular environmental policies, we are making decisions that will determine the kind of world our child and grandchildren will inherit. Since these decisions are so important, it stands to reason that we need these decisions to be the product of careful research and thoughtful reasoning, which are the hallmarks of critical thinking.

For diagramming using a modified Beardsley-Freeman model, the claims are put into boxes, the inferential connections are represented by arrows, and all the excess verbiage is removed (see figure 13.1).

In what follows, we argue that teaching argument analysis skills in a firstyear composition course using a modified version of the Beardsley-Freeman model of diagramming is better than doing so using the Toulmin model. To make this case, we first explore the nature and importance of critical thinking skills in the twenty-first century. We then explore the mounting evidence that teaching argument diagramming is a good way to improve students' critical thinking skills. The method one uses for diagramming arguments, however, depends on one's theory of argumentation, so we analyze Toulmin's theory and its conceptual and pedagogical problems. We then describe the development of a modified Beardsley-Freeman method of argument diagramming, as well as the results of a study we conducted to test the difference between teaching using the Toulmin method of argument diagramming and using the modified Beardsley-Freeman method.

\section{The importance of critical thinking skills}

Completion of at least one critical thinking course is a requirement at many colleges and universities in the United States (e.g., California State University, State University of New York, San Francisco State University, Pomona College) 


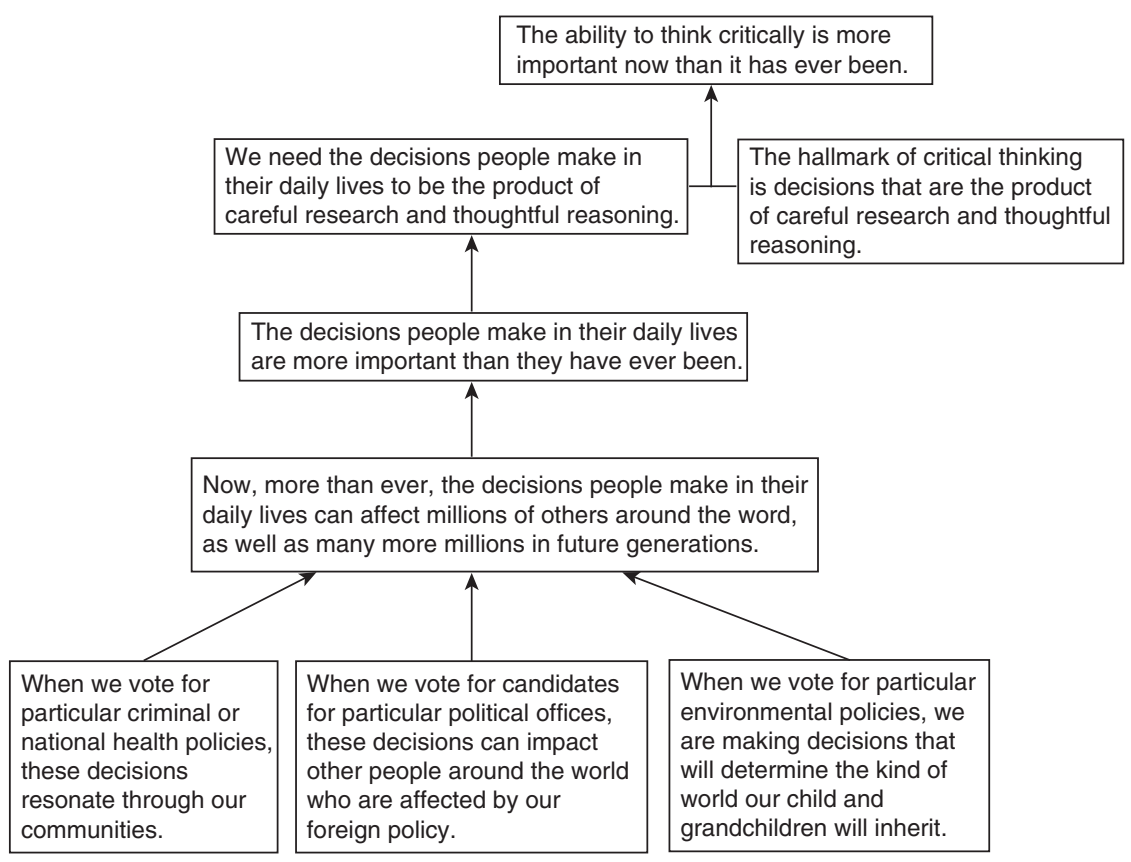

Figure 13.1 An argument diagram representing an argument for the importance of critical thinking.

and in other countries around the world (e.g., Athabasca University, Canada, McMaster University, Canada, Atkinson College, Canada, Universiteit Maastricht Faculty of Law, The Netherlands, Al Akhawayn University, Morocco, Edith Cowan University, Australia, Australian Catholic University, Australia, Charles Sturt University, Australia). In addition, many more colleges and universities have "development of critical thinking skills" or similar language as a part of the mission statement of the institution (e.g., Washburn University, Iowa State University).

In the United States, these requirements may have been based on the mounting evidence that, as a nation, our efforts to impart these skills are woefully inadequate. In 2008, only 13\% of American 13-year-olds and 39\% of American 17 -year-olds could "understand complicated information" and "learn from specialized reading materials" (Rampey, Dion, and Donahue 2009), and in 2011, only $27 \%$ of American eighth graders and $27 \%$ of American twelfth graders performed at or above "proficient" on a nationally administered writing test (National Center for Education Statistics 2012). College presidents note a rising tide of freshmen unprepared for the intellectual rigors of college, and employers observe that college graduates are seldom prepared for the rigors of the twenty-first-century workplace. 
Philosophers of education have said that the development of these skills should be the first priority of any educational activity (Siegel 1980; 1988), and a number of national advisory councils in the past two decades have cited the development of critical thinking skills of our nation's youth during secondary and postsecondary education as one of our most important challenges (Honey, Fasca, Gersick, Mandinach, and Sinha 2005; National Commission on Excellence in Education 1985; Rothman, Slattery, Vranek, and Resnick 2002). Indeed, the development of critical thinking skills is a part of the educational objectives of most universities and colleges, and the possession of these skills is one of the most sought-after qualities in a job candidate in many fields (Bieda 2011; Casserly 2012; Graves 2013).

Although there is no generally accepted, well-defined list of skills that constitutes the set we call "critical thinking skills," there seems to be fair agreement on the types of skills to which educators are referring when they speak about teaching critical thinking to their students. Many of these skills have been identified broadly as a global package of knowledge and behaviors (Brookfield 1987; Ennis 1987; Nickerson 1987; Resnick 1987), or more specifically as a deliberative activity (Carey 2000; Kurfiss 1988).

Even though there are a few generally accepted measures of these skills (e.g., the California Critical Thinking Skills Test and the Watson Glaser Critical Thinking Appraisal, but see also Halpern [1996] and Paul, Binker, Jensen, and Kreklau [1990]), there is surprisingly little research on effective methods for improving the critical thinking skills of college students. The research that has been done shows that the population in general has very poor skills (Kuhn 1991; Means and Voss 1996; Perkins, Jay, and Tishman 1992), and that very few college courses actually improve these skills (Annis and Annis 1979; Pascarella 1989; Resnick 1987; Stenning, Cox, and Oberlander 1995).

Most philosophers and educators agree that one aspect of critical thinking involves the ability to reconstruct, understand, and evaluate an argumenttasks we may call, for the sake of brevity, "argument analysis." For example, Kuhn (1991) says that "argumentative reasoning skills are in fact fundamental to what educators call 'critical' thinking" (5), and Ennis (1987) says that "analyzing arguments" is one of the critical thinking abilities. This covers identifying the stated and unstated premises and the conclusion, and "seeing the structure of an argument" (12).

\section{Teaching critical thinking skills}

Although critical thinking courses are required at several universities, many, if not most, undergraduate students never take a critical thinking course in their time in college. There may be several reasons for this: the classes are too hard to 
get into, the classes are not required, the classes do not exist, students' schedules are already overloaded, etc. It is difficult to understand, though, why any of these would be the case since the development of critical thinking skills is a part of the educational objectives of most universities and colleges, and since the possession of these skills is one of the most sought-after qualities in a job candidate in many fields.

Perhaps, though, both the colleges and employers believe that the ability to reason well is the kind of skill that is taught not intensively in any one course, but rather across the curriculum, in a way that would ensure that students acquired these skills no matter what major they chose. The research seems to show, however, that this is not the case; on tests of general critical thinking skills, students average a gain of less than one standard deviation during their entire time in college, while most of this gain comes just in the first year (Arum and Roska 2011; Pascarella 1989; Pascarella and Terenzini 2005).

Recent research, however, suggests that students' critical thinking skills do improve substantially if they are taught how to construct argument diagrams to aid in the understanding and evaluation of arguments. Some of these studies have shown that instruction that includes the students' critical thinking skills over the course of a semester (Dwyer, Hogan, and Stewart 2012; Harrell 2008; 2011; 2012). Other studies have shown the advantages of using argument diagrams to enhance comprehension and recall (Dwyer, Hogan, and Stewart 2010; Dwyer, Hogan, and Stewart 2013). In addition, studies specifically on computer-supported argument visualization have shown that the use of software specifically designed to help students construct argument diagrams significantly improves critical thinking abilities over the course of a semester undergraduate course (Davies 2012; Kirschner, Shum, and Carr 2003; Twardy 2004; van Gelder, Bissett, and Cumming 2004), or a semester of graduate-level work (Carrington, Chen, Davies, Kaur, and Neville 2011; Pinkwart, Ashley, Lynch, and Aleven 2009). Additionally, research in this area has shown that student's critical thinking about specific topics is improved if students collaborate on argument diagram instruction instead of working alone (Scheuer, McLaren, Harrell, and Weinberger 2011a; 2011b).

\section{Two models for argument analysis}

Most scholars, if they have any experience with argument diagrams at all associate these diagrams with Stephen Toulmin's seminal work The Uses of Argument (1958) (see figure 13.2). But the history of argument diagramming begins much earlier, in the previous century (for an overview of the historical development of argument diagramming see Reed, Walton, and Macagno 2007). 


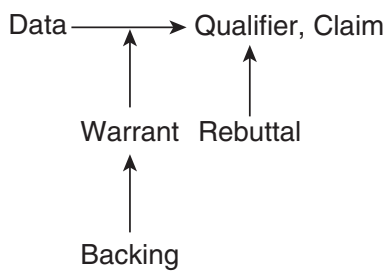

Figure 13.2 Toulmin's example of his model of argument diagramming $(1958,97)$.

What was revolutionary about Toulmin's approach is the emphasis he placed on needing a method of understanding and evaluating ordinary human rational discourse. Toulmin criticizes the philosophical discipline for focusing nearly exclusively on formal logic and the relationship between logic and mathematics. It had lost sight, he says, of the original motivation: studying actual human reasoning. Toulmin exhorted philosophy to focus more on real (messy) arguments and less on the artificial valid argument forms with which they were concerned.

Thus, Toulmin ushered in a new focus on what we now call "informal logic." However, Toulmin was not the only philosopher interested in emphasizing informal logic. In the 1980s and 1990s, James Freeman developed an alternative method for diagramming arguments. These different methods of argument representation are ultimately based on different theories of basic argument structure. Any theory of argument structure identifies the fundamental elements of arguments and describes how these elements fit together. Both Toulmin and Freeman take an argument to be made up of statements, in which one is the conclusion and others are offered in support of that conclusion. From there, however, their theories diverge.

\section{Toulmin}

In Toulmin's theory, there is only one pattern of argument made up of six different elements. Not all of these elements, though, describe kinds of statements, so Toulmin believes that an argument is more than just a collection of statements. There are three basic elements in an argument. The first is the claim, which is the original statement controversially asserted to be true. The second is the data, which are the reasons offered to support the claim. Finally, there is the warrant, which is offered as the link between the data and the claim, the fact that makes it so the data really do support the claim.

There are also three additional elements in an argument, according to Toulmin. There is the backing, which is offered as a reason for accepting the warrant. There is the qualifier, which indicates whether the data are supposed to be conclusive proof of the claim. And there is the rebuttal, which lays out the conditions under which the data do not, in fact, support the claim. 
In Toulmin's theory, claims, data, and backing are clearly statements that appear in the argument. And, just as clearly, qualifiers and rebuttals are not statements ("Qualifiers" are words like "usually," "mostly," or "probably," while "rebuttals" are words like "unless" or "except."). Warrants, on the other hand, are not as well defined. Toulmin describes warrants as statements, but often (though not always) says or implies that they are always implicit.

Every argument, then, according to Toulmin, consists of at least a claim that is explicitly supported by data, plus a warrant that implicitly sanctions the inference from the data to the claim. Some arguments have, in addition, backing, qualifier, and/or rebuttal, depending on the nature of the data and the claim.

In representing an argument diagrammatically, Toulmin introduces arrows to his set of six elements. Arrows can begin with either data or backing and end in a qualifier, claim, or warrant. Or, arrows can begin with warrant or rebuttal and end in another arrow. Thus, on the one hand, Toulmin employs a complicated ontology in his theory of argument: six different elements, only some of which are different kinds of statements, and at least two different kinds of connections only some of which are between different elements.

On the other hand, Toulmin's argument pattern is quite simple. On this model, different, independent reasons to believe a claim can only be treated as separate arguments, and objections to the claim, or to the data or backing can also only be treated as separate arguments. (While it may sound like an objection, a rebuttal on Toulmin's model is actually just another kind of qualifier, representing circumstances in which it is acknowledged that the data do not support the claim.)

\section{Beardsley-Freeman}

In his Dialectics and the Macrostructure of Arguments: A Theory of Argument, James Freeman (1991) credits Monroe Beardsley's Practical Logic (Beardsley 1950, subsequently published as Thinking Straight; 1966), with what he calls the "standard method" of argument diagramming. Freeman combines this method with the argument patterns identified by Stephen Thomas in Practical Reasoning in Natural Language (1986) to offer an alternative theory of argument to Toulmin's. In so doing, he created what we now call the Beardsley-Freeman (B-F) method of argument diagramming.

The first important departure from Toulmin's theory is Freeman's insistence on a simpler ontology. In Freeman's theory, there are only two basic elements that constitute an argument—premises and conclusions-and they are both different kinds of statements. There are however, five basic argument patterns that Freeman acknowledges, as opposed to only one acknowledged by Toulmin. The first is the simplest: one premise that supports one conclusion. The other four patterns require at least three statements. The first is a divergent argument, in which 
one premise supports two different conclusions. The second is a serial argument, in which one premise supports another premise, which in turn supports the conclusion. Third is a convergent argument, in which two premises each offer independent support for the conclusion. And the last is a linked argument, in which two premises must work together to provide support for the conclusion.

On the B-F model of diagramming, then, all the statements in an argument are numbered. The statements are then represented by their corresponding numbers in circles, and the inferential connections between statements are indicated by arrows. Here, there is only one kind of arrow, one that begins at a premise (or premises) and ends in a conclusion. The four patterns involving more than two statements above are represented as diagrams in figure 13.3.

According to Freeman, these patterns can accurately represent any argument, no matter how complicated. Serial arguments can be made up of chains of premises of an arbitrary length, convergent arguments may have many more than just two premises supporting the conclusion, and one can link many premises together if necessary to support a conclusion. In addition, all of these elements may be combined in any way necessary to represent a single complex argument, as shown in figure 13.4.
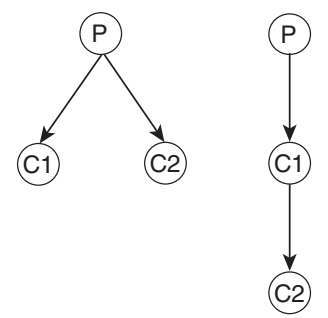

Divergent

Serial

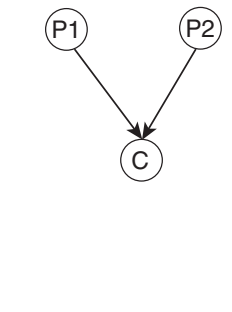

Convergent

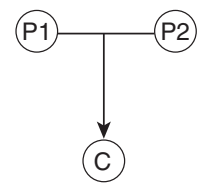

Linked

Figure 13.3 Freeman's example of the B-F method of diagramming the four basic argument patterns involving more than two statements $(1991,2)$.

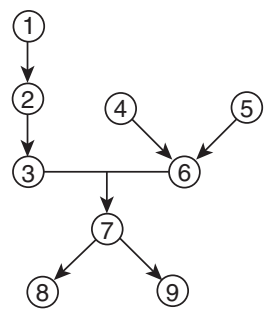

Figure 13.4 Freeman's example of a diagram of a complex argument that combines the basic elements for an accurate representation $(1991,2)$. 


\section{Using Toulmin's method of argument analysis in writing courses}

Many colleges and universities across the United States require a general purpose writing or composition course for all students. For example, University of Michigan, University of Minnesota, North Carolina State University, Kent State University, George Washington University, Clemson University, Wellesley College, Swarthmore College, and Amherst College all have versions of this course required of every first-year student. These courses have slightly different course objectives, but a common thread is that students will learn how to analyze arguments in academic texts and create their own arguments-developing thesis statements, marshaling evidence, and synthesizing research-in addition to learning to write in a variety of genres and communicating through various media.

One of the perennial challenges of these kinds of courses is the wide variation in the background knowledge and skills each student brings to the class. Most students in American high schools learn how to write the standard "five paragraph essay," but the emphasis on rigorous argumentation can be variable. (The "five paragraph essay" is a one-paragraph introduction with a thesis statement, a one-paragraph conclusion that rephrases the introduction, and three body paragraphs. The body paragraphs each contain one argument, example, or illustration, and the template calls for the strongest to come in the first body paragraph, and the weakest to come in the third.) In addition, high school students in countries outside the United States can have wildly differing experiences of reading and writing in an academic context. Thus, most students have little experience analyzing arguments when they first arrive on a college campus. The composition teacher, then, has her work cut out for her.

For this reason alone, Toulmin's impact in various academic fields cannot be overstated. Almost immediately after the publication of The Uses of Argument in1958, there were calls for Toulmin's model of argument representation to be incorporated into the pedagogical practices of teachers in many disciplines. For example, the Toulmin model was widely adopted by speech departments across the United States, partly due to Wayne Brockriede and Douglas Ehninger urging rhetoricians to pay attention to this landmark book. "Toulmin's analysis and terminology are important to the rhetorician...they provide an appropriate structural model by means of which rhetorical arguments may be laid out for analysis and criticism" (Brockriede and Ehninger 1960, 46).

By two decades after its publication, Toulmin's Uses of Argument was exerting a huge influence. In urging those in composition studies to adopt the Toulmin model, Charles Kneupper claims that "speech instruction has largely abandoned the syllogistic paradigm, and most recent texts in public speaking, argumentation, and persuasion are now using a model of argument developed by 
the philosopher, Stephen Toulmin" (Kneupper 1978, 237). In the same article, Kneupper explains that teaching students to read for an argument is notoriously difficult, and he pushes Toulmin's method as a way to make this task easier (Kneupper 1978, 237-240).

The advice of Brockriede and Ehninger, as well as Kneupper, seems to have been heeded. In a citation analysis, Ronald Loui found that "everyone associated with scholarship in rhetoric, dialectic, or informal logic seems to have read Toulmin's 'Uses of Argument'" (Loui 2005, 266). One of the reasons offered for this broad impact is that Toulmin's model is simpler and less cumbersome than formal logic (Fulkerson 1986; Gross 1984).

Developing argument analysis skills can be difficult, especially for first-year students who may have to unlearn bad habits developed in high school. For this reason, more than a decade ago, we followed this trend in using the Toulmin method to teach argumentation at Carnegie Mellon University (CMU), in our First-Year Writing (FYW) Program. The broad purpose of this program is to develop academic reading and writing skills each student needs to be successful in his or her college career. Each student at CMU must take the course "Interpretation and Argument," which is the core of this writing program.

Thus, though not titled "Critical Thinking," the FYW course taken during the first year is generally one of the student's first introductions to important aspects of thinking critically at a college level. Among other goals, the specific learning objectives for the FYW Program is for students to be able to:

1. Analyze a written argument: identify the conclusion and the premises (both implicit and explicit) and describe how the premises support the conclusion.

2. Evaluate a written argument: determine whether the premises do in fact support the conclusion, and determine whether the premises are reasonable.

3. Write an essay: analyze and evaluate one or more arguments.

The goal for the FYW course is to provide foundational reading and writing skills that will enable students to develop advanced literacy in their own disciplines.

Recently, however, we have realized that most of the teachers of the FYW course encounter some serious difficulties when teaching the Toulmin method of argument analysis to their students. And we are not alone. There is mounting evidence that teachers in all disciplines are facing hurdles using the Toulmin model. In particular, the notion and identification of "warrants" in an argumentative text is notoriously difficult to teach (Brunk-Chavez 2004; Fulkerson 1996a; Rex, Thomas, and Engel 2010; Warren 2010). As Warren says, "Teaching students to identify warrants can be so difficult that many teachers simply omit them when teaching the Toulmin model" $(2010,41)$. In 


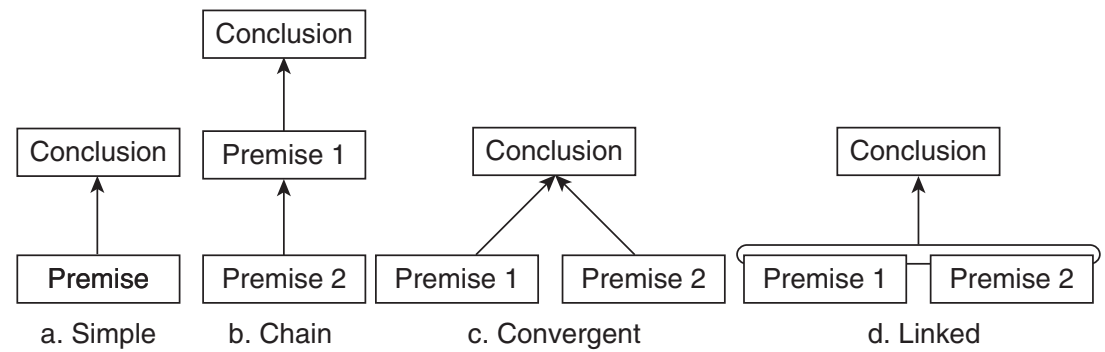

Figure 13.5 The CMU method of diagramming the four basic argument patterns.

fact, this difficulty with warrants is not restricted to students; composition instructors also find warrant identification difficult (Fulkerson 1996b, 62; Warren 2010, 43).

Thus, in the past few years, we have incorporated a new argument diagramming curriculum into the FYW course, based on the B-F model articulated above. Like the B-F model, in the CMU model, there are only two main categories of statements: premises and conclusions. In detailed analysis, there can be different kinds of premises: subconclusions, implicit premises, objections, etc. Instead of numbering the statements, though, they are rewritten and put into boxes. The boxes are then connected by arrows representing the inference(s) from premise(s) to (sub-)conclusion. In the CMU model, there are four basic argument structures. The simplest is one premise supporting one conclusion (figure 13.5a). Like the B-F method, the other three structures are chain (serial), convergent, and linked (figures $13.5 \mathrm{~b}-\mathrm{d}$ ), and these structures can be combined in any way necessary to accurately represent any argument.

The reader may notice that we have inverted the diagrams compared to the B-F method outlined above. This is deliberate. The B-F method was developed to mirror traditional formal logical proofs that start with the given premises at the top and work their way down to the conclusion at the bottom. Our thinking, however, is to use the metaphor of a premise supporting a conclusion like a foundation supports a house to make the direction of the arrows easier for students to understand.

\section{Using the CMU argument diagramming model}

We have developed an argument diagramming curriculum that is used in many of our classes. The curriculum includes an online tutorial (citation) and a series of in- and out-of-class practice activities with diagramming throughout the semester. The online tutorial defines an argument as a set of statements, one of which is the conclusion, and the others are premises, where the premises 
are supposed to provide support for the conclusion. Most importantly, the exercises in the tutorial teach the students how to

- identify premises and conclusions using indicator words and phrases in the text,

- identify linked, convergent, and chain arguments using indicators,

- identify subarguments,

- identify implicit premises and conclusions,

- diagram arguments using a specialized software program,

- interpret an argument according to the principles of fairness and charity, and

- diagram objections and replies.

Our move to use this method has enabled us to dodge some problems that we had previously encountered when using the Toulmin model of argument. As reading and writing teachers, our interest in using any kind of heuristic for reading and writing is to facilitate rhetorical invention for analysis and production. The CMU diagramming method and vocabulary, because of its simplicity, has allowed us to apply it across a variety of texts from the wild (i.e., a variety of texts from a variety of contexts), has allowed us to both identify and name parts of the arguments, also visualize those parts, and how they connect together.

Specifically, the method has helped us remedy two particular areas where teachers found themselves becoming "stuck" with the students in the course. The first problem related to the argument vocabulary that we had been using. The second problem stemmed from the fact that our methods, to that point, were insufficient for representing a whole argument at one glance. Together, these two problems merged into an overarching issue: How could students identify pieces of an argument within their reading and represent that argument visually, if the vocabulary for identification was so complicated that they became bogged down in the process of identification?

We had been using Toulmin to teach analytical reading in our FYW course because the students needed a vocabulary for discussing parts of an argument. What the teachers enjoyed from the Toulmin model was the concept of warrant. For Toulmin, a warrant connects the data or "facts" with claims within an argument. Toulmin, Rieke, and Janik describe warrants as implied generalizations that individuals consider to be trustworthy (Toulmin, Rieke, and Janik 1984, 45). The authors go on to explain that constructing effective arguments depends upon the kinds of "general ways of arguing we are going to rely on, and employ, in this particular case" (Toulmin, Rieke, and Janik 1984, 48). These warrants, according to the authors, are situated, context dependent, and field- or discipline specific. 
Prior to using the CMU diagramming method, however, students found that Toulmin's concept of warrant (as explained above) was something that they struggled with early in their argument analyses processes. Some students struggled with distinguishing between "data" and "warrant," especially whenever a warrant was an explicit one within the text. In no way do we mean to imply that our students could not eventually understand the concept of warrant. Rather, the nuances of the concept became nearly impossible to navigate within the context of an academic writing course simply because there is a limited amount of time to spend on these terms in light of the course objectives. By the end of the course, the students are not only analyzing individual arguments but are building research syntheses and their own inquiry-driven, written contributions. In order to get students from writing an analysis of one text, to a synthesis and analysis of a field of texts, and then to authoring their own research questions and contributions, teachers could not spend much time problematizing the argumentative heuristic vocabulary. The objective of the course is to give students resources, or flexible tools, that they can apply to text analysis and production. If the students could not trust these tools, they would not be able to (or even wish to) use them. We found that students enjoyed analyzing and discussing warrants but that they could not use the concept of warrant for analyzing their own writing or that of their peers to help them with revision.

The argument vocabulary, according to the CMU diagramming method, is a simple one. All elements in an argument can be identified as statements. Those statements can be further classified as conclusions, subconclusions, premises, and implied premises. (There are other vocabulary items as well, but these are the items relevant for this discussion.) Most usefully, though, the CMU method has simplified the use of the term warrant through its use of the term implied premise. An implied premise can be a statement of any sort, not just the kind of "if, then" statements that Toulmin, in various places, seems to require. Representing an argument as a whole is much easier with a more streamlined vocabulary because the students spend less time struggling with their comprehension of "data," "warrant," "backing," and so forth. Therefore, students can move toward seeing connections between the "chunks" of arguments and visualizing the argument as a whole.

Students' cognitive burden has been reduced for representing a whole argument visually. The vocabulary and structure of conclusion-subconclusion-premise enables us to build, rather quickly, visual representations of texts because the number of textual categories is not an overwhelming one. The categories themselves reduce the "noise" that a reader might experience when identifying and classifying statements for the purpose of diagramming their relationships. Each item, whether a statement about data, explanation, or reasoning, fits under another statement. Because the structure 
allows students to think in terms of how the pieces fit together, students can more quickly move toward evaluating the logical they have diagrammed.

We should note that this more streamlined vocabulary and structure does not preclude the teacher from introducing the concept of warrant later in the course-or other terms in argument theory that might highlight the rhetorical situation of a text, its purpose and audience, and its overall social context. However, students will have already learned how to identify structures within the arguments they read before grappling with other argument terms. Some examples of other terms that teachers have used to discuss types of statements within the argument diagramming structure include not only Toulmin's terms (e.g., claims that function as warrants), but also stasis terms (e.g., definition or causal claims), rhetorical proofs (e.g., ethical claims), and policy concepts (e.g., problem statements). In these ways, teachers have been able to address a variety of texts through the diagramming heuristic.

\section{Effectiveness of the CMU argument diagramming method}

Recently, we presented the data from a study we conducted testing the hypothesis that students in the FYW courses who learn the CMU model of argument diagramming will improve in performance on argumentative writing tasks over the course of a semester-long composition class significantly more than students in the FYW courses who do not (Harrell and Wetzel 2013).

In the Fall of 2009, and the Spring and Fall of 2010, we administered pre- and post-tests to 81 students in the FYW program. Each test consisted in reading some text and completing two tasks. In Task 1 , the student was asked to write an essay analyzing the argument presented by the author in the text. This analysis was to consist in identifying both the content and the structure of the argument. In Task 2, the student was asked to write an essay evaluating the argument presented by the author in the same text. The evaluation was to consist a claim about the quality of the argument and reasons to support that claim.

We recognize that text features alone do not constitute "good writing" and that there is no "right way" to read or write a text. We also recognize that privileging some text features over others might ignore other significant features. The features that we chose will help us locate change in demonstrable critical thinking between the pre-test and post-test. We analyzed the texts for markers of text development and text coherence. We were interested in seeing to what extent there would be any kind of change in how many different ideas students could generate-about someone else's argument and about their own arguments. Within this category of "development," we identified the following for both Tasks 1 and 2 of the pre- and post-tests: the number of different reasons or 
premises offered for the argument conclusion, and the number of counterarguments considered within the text.

For Task 1, we wanted to determine how much the students could understand the argument in the text and what statements they would prioritize in their representations of it. For Task 2 alone, we also considered whether students provided evidence or elaboration of their reasons. We wanted to distinguish between reasons that were supported with evidence and those that were not. Our concern was instances when students produced a lot of different ideas but failed to support them; we did not want to report "growth" in development without attempting to represent to what extent students were actually supporting their claims.

Because the number of ideas alone does not necessarily equate with good writing, and, in fact, one could argue that too many different ideas within an argument will result in chaos for a reader, we also looked for features that signaled an overall coherence in a written text. Vande Kopple has defined coherence as "prose in which nearly all the sentences have meaningful connections to sentences that appear both before and after them" $(1989,2)$. We also draw upon Enkvist's definition of coherence, "the quality that makes a text conform to a consistent world picture and is therefore summarizable and interpretable" $(1990,49)$. So, by coherence, we mean those features that enable a reader to make particular kinds of connections within the text. In coding Task 1 , we considered the following as coherence markers: logical connections between premises and the argument conclusion and logical connections between different premises.

In coding Task 2, we looked at the following as markers of coherence: logical connections between premises and the argument conclusion, logical connections between different premises, and metacommentary (or "metadiscourse"). Metacommentary is language that writers use, according to Hyland (2003), to compose a text that is clear to a reader.

By providing linguistic "signposts" to readers, writers can create the effect that a text is coherent and holds together in an intentional way. Because these bits of language give clues for making sense of the text, their presence in a text can indicate that a writer is aware of a reader's needs for navigating the text successfully. These bits of language can also show that a writer understands his or her own text in particular ways and can point to a writer's strategic view of his or her writing. For this study, we were only interested in the effect that metacommentary has upon the readers-we were not interested in counting the different types. Therefore, coders scored Task 2 holistically for effective use of metacommentary.

The results from Task 1 (given in figure 13.6) show that, when reading an argument, students who were taught argument diagramming were significantly more likely than those who were not to identify more of the relevant 


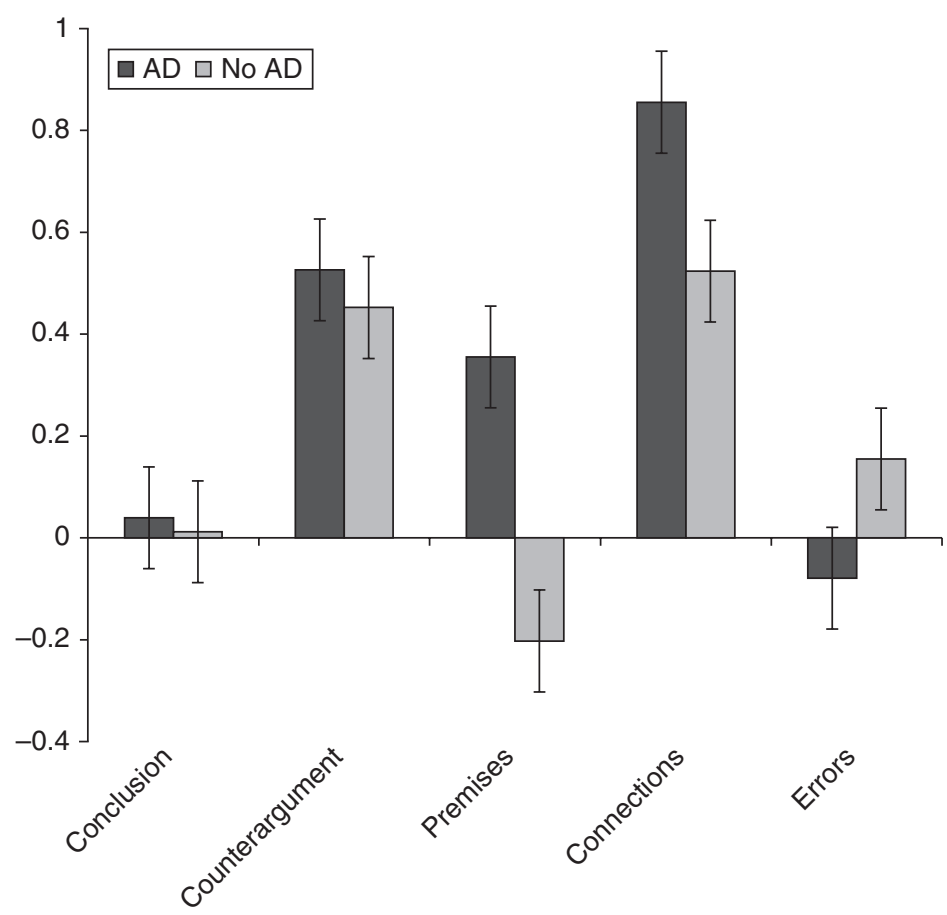

Figure 13.6 Comparisons of gains in each category of Task 1 from pre-test to post-test for students who were and were not taught argument diagramming.

premises offered that support the author's conclusion, and explain more explicitly how the premises are supposed to work together to support the conclusion. In addition, these students were much less likely to make any errors in their analysis.

The results from Task 2 (given in figure 13.7) show that, when evaluating the argument in a text, students who were taught argument diagramming improved significantly more than those who were not in their ability to (1) provide more premises to support their own thesis, (2) offer more evidence in support of each premise, (3) have fewer mismatches between premises and evidence, (4) explain more explicitly how the premises are supposed to work together to support the conclusion, (5) offer possible counterarguments, and (6) provide metacommentary on their response.

Thus, it seems that students who were taught argument diagramming are developing new schema for reading arguments and learning how to effectively translate this into their own writing. This is reflected most noticeably in the improvement of the metacommentary from pre-test to post-test. We conclude that incorporating argument diagramming into the curriculum of Interpretation and Argument is positively beneficial to realizing several of our course objectives. 


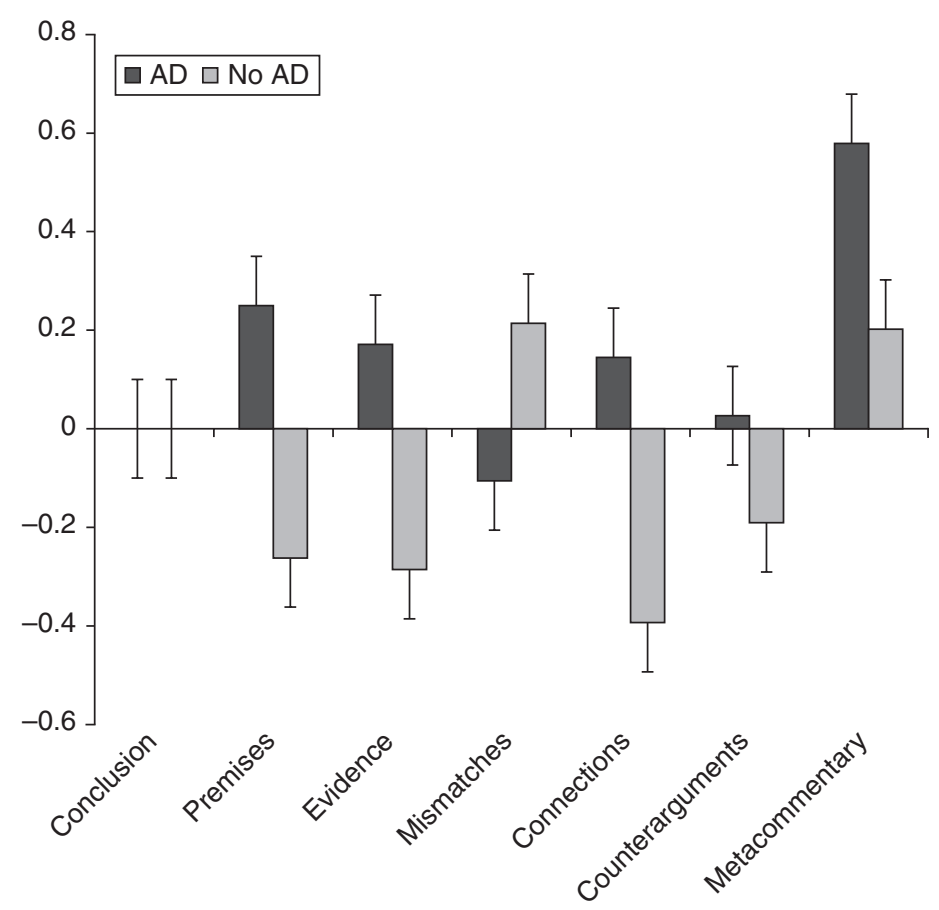

Figure 13.7 Comparisons of gains in each category of Task 2 from pre-test to post-test for students who were and were not taught argument diagramming.

\section{Conclusion}

Because of our personal experience teaching in the FYW program, talking to others who teach in the program, and the studies we have conducted, we have concluded that teaching argument analysis skills using our modified B-F argument diagramming method is superior to using the Toulmin method.

These results are important because the creation of one's own arguments as well as the analysis of others' arguments occur in nearly every discipline, from Philosophy and Logic to English and History to Mathematics and Engineering. We believe that the use of argument diagrams, and the CMU diagramming method in particular, would be helpful in any of these areas, both in developing general critical thinking skills and in developing discipline-specific analytic abilities.

\section{Acknowledgments}

We would like to thank David Danks, Martin Davies, and three anonymous reviewers for their helpful comments. This study was funded by a joint grant from the Spencer Foundation and the Teagle Foundation, under the title "Systematic Improvement of Undergraduate Education in Research Universities." 


\section{References}

Annis, D., and Annis, L. 1979. "Does Philosophy Improve Critical Thinking?" Teaching Philosophy 3: 145-152.

Arum, R., and Roska, J. 2011. Academically Adrift: Limited Learning on College Campuses. Chicago and London: University of Chicago Press.

Beardsley, M. C. 1950. Practical Logic. (third edition). Englewood Cliffs, NJ: Prentice Hall.

Beardsley, M. C. 1966. Thinking Straight. (third edition). Englewood Cliffs, NJ: Prentice Hall.

Bieda, A. S. 2011. Closing the Gap between Career Education \& Employer Expectations: Implications for America's Unemployment Rate. Washington, DC: Accrediting Council for Independent Colleges and Schools.

Brockriede, W., and Ehninger, D. 1960. "Toulmin on Argument: An Interpretation and Application." Quarterly Journal of Speech 46: 44-53.

Brookfield, S. 1987. Developing Critical Thinkers: Challenging Adults to Explore Alternative Ways of Thinking and Acting. San Francisco: Jossey-Bass.

Brunk-Chavez, B. L. 2004. "What's So Funny about Stephen Toulmin? Using Cartoons to Teach the Toulmin Analysis." Teaching English in the Two Year College 32 (2): 178-185.

Carey, S. S. 2000. The Uses and Abuses of Argument. Mountain View, CA: Mayfield.

Carrington, M., Chen, R., Davies, M., Kaur, J., and Neville, B. 2011. "The Effectiveness of a Single Intervention of Computer-Aided Argument Mapping in a Marketing and a Financial Accounting Subject." Higher Education Research and Development 30 (3): 387-403.

Casserly, M. 2012. The 10 Skills That Will Get You Hired in 2013. December 12, 2013. Available from http://www.forbes.com/sites/meghancasserly/2012/12/10/the-10-skills -that-will-get-you-a-job-in-2013/.

Davies, M. 2009. "Computer-Assisted Argument Mapping: A Rationale Approach." Higher Education 58 (6): 799-820.

Davies, M. 2012. "Computer-Aided Argument Mapping and the Teaching of Critical Thinking (Part 2)." Inquiry: Critical Thinking across the Disciplines 27 (3): 16-28.

Dwyer, C. P., Hogan, M. J., and Stewart, I. 2010. "The Evaluation of Argument Mapping as a Learning Tool: Comparing the Effects of Map Reading versus Text Reading on Comprehension and Recall of Arguments." Thinking Skills and Creativity 5: 16-22.

Dwyer, C. P., Hogan, M. J., and Stewart, I. 2012. "An Evaluation of Argument Mapping as a Method of Enhancing Critical Thinking Performance in E-Learning Environments." Metacognition Learning 7: 219-244.

Dwyer, C. P., Hogan, M. J., and Stewart, I. 2013. "An Examination of the Effects of Argument Mapping on Students' Memory and Comprehension Performance." Thinking Skills and Creativity 8: 11-24.

Enkvist, N. E. 1990. "Seven Problems in the Study of Coherence and Interpretability." In Coherence in Writing: Research and Pedagogical Perspectives, edited by Ulla Connor and Ann M. Johns. Alexandria, VA: Teachers of English to Speakers of Other Languages, Inc.

Ennis, R. H. 1987. "A Taxonomy of Critical Thinking Dispositions and Abilities." In Teaching Thinking Skills: Theory and Practice, edited by J. B. Baron and R. J. Sternberg. New York: W. H. Freeman and Company. 9-26.

Freeman, J. B. 1991. Dialectics and the Macrostructure of Arguments: A Theory of Argument Structure. New York: Foris Publications.

Fulkerson, R. 1986. "Logic and Teachers of English?" Rhetoric Review 4 (2): 198-209.

Fulkerson, R. 1996a. "Stephen Toulmin." In Encyclopedia of Rhetoric and Composition. New York: Garland 726-727. 
Fulkerson, R. 1996b. "The Toulmin Model of Argument and the Teaching of Composition." In Argument Revisited; Argument Redefined; Negotiating Meaning in the Composition Classroom, edited by Barbara Emmel, Paula Resch and Deborah Tenney. Thousand Oaks, CA: American Forensic Association, Sage Publications. 45-72.

Graves, J. A. 2013. 7 Key Skills You Need to Get Hired Right Now: In-Demand Skills Job Candidates Must Cultivate. February 24, 2013. Available from http://money.usnews .com/money/careers/articles/2013/02/21/7-key-skills-you-need-to-get-hired-right-now.

Gross, A. G. 1984. "A Comment on the Uses of Toulmin." College English 46 (3): 310-314 http://www.jstor.org/stable/377043.

Halpern, D. 1996. Thought and Knowledge: An Introduction to Critical Thinking. (third edition) Mahwah, NJ.: Lawrence Erlbaum Associates.

Harrell, M. 2008. "No Computer Program Required: Even Pencil-and-Paper Argument Mapping Improves Critical Thinking Skills." Teaching Philosophy 31: 351-374.

Harrell, M. 2011. "Argument Diagramming and Critical Thinking in Introductory Philosophy." Higher Education Research and Development 30 (3): 371-385.

Harrell, M. 2012. "Assessing the Efficacy of Argument Diagramming to Teach Critical Thinking Skills in Introduction to Philosophy." Inquiry 27 (2): 31-38.

Harrell, M., and Wetzel, D. 2013. "Improving First-Year Writing Using Argument Diagramming." In M. Knauff, M. Pauen, N. Sebanz, and I. Wachsmuth, Proceedings of the 35th Annual Conference of the Cognitive Science Society (pp. 2488-2493). Austin, TX: Cognitive Science Society.

Honey, M., Fasca, C., Gersick, A., Mandinach, E., and Sinha, S. 2005. Assessment of 21st Century Skills: The Current Landscape. New York: Partnership for 21st Century Skills.

Hyland, K. 2003. Second Language Writing. Cambridge: Cambridge University Press.

Kirschner, P. A., Shum, S. J. B., and Carr, C. S. 2003. Visualizing Argumentation: Software Tools for Collaborative and Educational Sense-Making. New York: Springer.

Kneupper, C. W. 1978. "Teaching Argument: An Introduction to the Toulmin Model." College Composition and Communication 29 (3): 237-241.

Kuhn, D. 1991. The Skills of Argument. Cambridge: Cambridge University Press.

Kurfiss, J. 1988. Critical Thinking: Theory, Research, Practice and Possibilities. Washington: ASHE-Eric Higher Education Report No. 2, Associate for the Study of Higher Education.

Loui, R. P. 2005. "A Citation-Based Reflection on Toulmin and Argument." Argumentation 19 (3): 259-266.

Means, M. L., and Voss, J. F. 1996. "Who Reasons Well? Two Studies of Informal Reasoning among Children of Different Grade, Ability, and Knowledge Levels." Cognition and Instruction 14: 139-178.

National Center for Education Statistics. 2012. "The Nation's Report Card: Writing 2011" NCES 2012-470. Washington, DC.

National Commission on Excellence in Education. 1985. "A Nation at Risk: The Imperative for Educational Reform: A Report to the Nation and the Secretary of Education." Washington, DC.

Nickerson, R. S. 1987. "Why Teach Thinking?" In Teaching Thinking Skills: Theory and Practice, edited by J. B. Baron and R. J. Sternberg. New York: Freeman. 27-37.

Pascarella, E. 1989. "The Development of Critical Thinking: Does College Make a Difference?" Journal of College Student Development 30: 19-26.

Pascarella, E., and Terenzini, P. 2005. How College Affects Students: Findings and Insights from Twenty Years of Research. Vol. 2: A Third Decade of Research. San Francisco: Jossey Bass.

Paul, R., Binker, A., K., J., and Kreklau, H. 1990. Critical Thinking Handbook: A Guide for Remodeling Lesson Plans in Language Arts, Social Studies and Science. Rohnert Park, CA: Foundation for Critical Thinking. 
Perkins, D., Jay, E., and Tishman, S. 1992. Assessing Thinking: A Framework for Measuring Critical Thinking and Problem Solving Skills at the College Level. Washington, DC: The National Center for Educational Statistics Workshop on the Assessment of Higher Order Thinking and Communication Skills of College Graduates: Preliminary listing of Skills and Levels of Proficiency.

Pinkwart, N., Ashley, K., Lynch, C., and Aleven, V. 2009. "Evaluating an Intelligent Tutoring System for Making Legal Arguments with Hypotheticals." International Journal of Artificial Intelligence in Education 19: 401-424.

Rampey, B. D., Dion, G. S., and Donahue, P. L. 2009. “Naep 2008 Trends in Academic Progress " NCES 2009-479. Washington, DC.

Reed, C., Walton, D., and Macagno, F. 2007. "Argument Diagramming in Logic, Law and Artificial Intelligence." The Knowledge Engineering Review 22: 87-109.

Resnick, L. B. 1987. Education and Learning to Think. Washington, DC: National Academy Press.

Rex, L. A., Thomas, E. E., and Engel, S. 2010. "Applying Toulmin: Teaching Logical Reasoning and Argumentative Writing." 99 (6): 56-62.

Rothman, R., Slattery, J. B., Vranek, J. L., and Resnick, L. B. 2002. "Benchmarking and Alignment of Standards and Testing." CSE Tech. Rep. 566. Los Angeles, CA.

Scheuer, O., McLaren, B., Harrell, M., and Weinberger, A. 2011a. "Scripting Collaboration: What Affects Does It Have on Student Argumentation?" In Proceedings of the 19th International Conference on Computers in Education: Icce 2011, edited by T. Hirashima, G. Biswas, T. Supnithi and F. Yu. Chiang Mai, Thailand: National Electronics and Computer Technology Center.

Scheuer, O., McLaren, B., Harrell, M., and Weinberger, A. 2011b. "Will Structuring the Collaboration of Students Improve Their Argumentation?" In Lecture Notes in Computer Science: Artificial Intelligence in Education-15th International Conference, edited by G. Biswas, S. Bull, J. Kay and A. Mitrovic. Berlin: Springer-Verlag, 6738. 544-546.

Siegel, H. 1980. "Critical Thinking as an Educational Ideal." Educational Forum 45 (1) $7-23$.

Siegel, H. 1988. Educating Reason: Rationality, Critical Thinking, and Education. New York: Routledge.

Stenning, K., Cox, R., and Oberlander, J. 1995. "Contrasting the Cognitive Effects of Graphical and Sentential Logic Teaching: Reasoning, Representation and Individual Differences." Language and Cognitive Processes 10 (3-4): 333-354.

Thomas, S. N. 1986. Practical Reasoning in Natural Language. (third edition). Englewood Cliffs, NJ: Prentice Hall.

Toulmin, S. E. 1958. The Uses of Argument (first edition). Cambridge, England: Cambridge University Press.

Toulmin, S. E., Rieke, R., and Janik, A. 1984. An Introduction to Reasoning. (second edition). New York, London: Macmillan Publishing Co., Inc. Collier Macmillan Publishers.

Twardy, C. R. 2004. "Argument Maps Improve Critical Thinking." Teaching Philosophy 27: $95-116$.

van Gelder, T., Bissett, M., and Cumming, G. 2004. "Cultivating Expertise in Informal Reasoning." Canadian Journal of Experimental Psychology 58: 142-152.

Vande Kopple, W. 1989. Clear and Coherent Prose: A Functional Approach. Glenview, IL: Scott, Foresman, \& Company.

Warren, J. E. 2010. "Taming the Warrant in Toulmin's Model of Argument." English Journal 99 (6): 41-46. 